\title{
“0 mercado é nosso amigo, nós é que não sabemos compreendê-lo": \\ o trading financeiro entre o otimismo quantitativo e a descrença
}

Daniel Seabra Lopes*

\section{Resumo}

Este artigo toma por objeto os índices financeiros, entendidos como expressões quantificadas do sentimento dos investidores e, ao mesmo tempo, como face visível do mercado. A constituição desses indicadores técnicos como objeto etnográfico permite alargar o âmbito da antropologia das emoções, abarcando dimensões da vida coletiva que vão muito para além da esfera das relações interpessoais e das micropolíticas, aceitando ao mesmo tempo que os números e gráficos podem efetivamente integrar o repertório discursivo da vida emocional. Num primeiro momento, é feita uma apresentação do modo como os mercados financeiros globais são vistos a partir de uma sala de mercados de um banco, passando em seguida a uma descrição etnográfica da atividade situada de um trader (corretor) dias antes do crash de setembro de 2008. 0 artigo prossegue descrevendo o modo como os índices financeiros passaram a ser encarados após o colapso de 2008 e o escândalo da manipulação da taxa Libor (2012), concluindo com uma reflexão sobre as valências de uma etnografia dos indicadores técnicos para a antropologia das emoções.

\section{Palavras-chave}

Indicadores financeiros. Bancos. Etnografia.

\footnotetext{
* Daniel Seabra Lopes é doutor em Antropologia Social e Cultural pela Universidade Nova de Lisboa. Trabalha como pesquisador no SOCIUS - Centro de Investigação em Sociologia Económica e das Organizações, sendo também professor auxiliar convidado no Instituto Superior de Economia e Gestão da Universidade de Lisboa. Foi pesquisador visitante na Universidade Estadual de Campinas (2014), na Universidade de Edimburgo (2014-2017) e na Faculdade de Sciences Po da Universidade Sorbonne-Paris (2017). O seu trabalho sobre banca e finança tem vindo a ser publicado numa série de revistas internacionais, nomeadamente European Societies, Social Anthropology, Economy and Society, Journal of Cultural Economy e Cultural Studies. Email: dseabralopes@gmail.com.
} 


\section{Abstract}

This article's object are the financial indexes, understood as quantified expressions of the investors' feeling and, at the same time, as a visible face of the market. The constitution of these technical indicators as an ethnographic object allows us to amplify the field of the anthropology of emotions, embracing dimensions of the collective life that go way beyond the scope of interpersonal and micropolitical relationships, at the same time accepting that numbers and graphics can effectively integrate the discursive repertoire of the emotional life. Firstly, there's a presentation on how the global financial markets are seen, starting with a market office in a bank, then coming to an ethnographic description of a trader's activity days before the crash of September 2008. The article carries on describing how the financial indexes were faced after the 2008 collapse and the scandal of the Libor tax manipulation (2012), concluding with a reflection on the values of an ethnography of the technical indicators for the anthropology of the emotions.

\section{Keywords}

Financial Indicators. Banks. Ethnography.

\section{Introdução}

Numa curta obra de introdução à antropologia econômica de Gabriel Tarde, Latour e Lépinay (2009, p.11-12) avançam a ideia de que tudo aquilo que nos habituamos a apreciar como uma qualidade seria no fundo a expressão de uma quantidade: a beleza, a utilidade ou a verdade de uma coisa estão intimamente relacionadas com o número de vezes em que essa coisa é valorizada como bela, útil ou verdadeira - um pouco à imagem, se quisermos, dos "gostei" das redes sociais virtuais (vide também LATOUR, 2010). Os mercados financeiros ilustram perfeitamente essa ideia. Uma vez consumada a plena informatização das propostas de negociação, a existência de tais mercados passou a depender significativamente da sua visualização em monitores (ou ecrãs) de computador, onde o volume das transações é traduzido graficamente. De acordo com Knorr-Cetina e Bruegger (2002a), o mercado constitui-se efetivamente como realidade agregada, consistente e autónoma apenas a partir do momento em que os seus índices são apresentados no espaço simbólico do monitor (ou ecrã) e podem ser observados de forma idêntica em qualquer lugar do mundo. 
Acresce que boa parte dos ativos transacionados em bolsa ou diretamente entre contrapartes não tem uma componente física: tanto as ações como as obrigações como os derivados financeiros só existem mesmo no ecrã, estando o seu valor monetário dependente do número de vezes em que, nos mais variados cantos do mundo, os negociadores vão clicando nas opções "buy" ou "sell". A atribuição de um valor monetário não é mais que a tradução da suposta qualidade do ativo e, no limite, da existência desse ativo, na medida em que um número exagerado de propostas de venda conduzirá à sua desvalorização e, eventualmente, à sua anulação contabilística.

O presente artigo propõe uma reflexão antropológica em torno dos índices financeiros, entendidos como expressões quantificadas dos sentimentos dos investidores - dos seus receios e esperanças, para recuperarmos os termos de Delumeau (1989, p. 22) -, que, em conjunto, perfazem ou performam a realidade do mercado. Encarar os índices financeiros como objeto etnográfico permite alargar o âmbito da antropologia das emoções de raiz contextualista inaugurada por Abu-Lughod e Lutz (1990), abarcando dimensões da vida coletiva para além da esfera das relações interpessoais e das micropolíticas e, paralelamente, aceitando que números e gráficos também possam integrar o repertório discursivo associado à vida emocional.

Por outro lado, pretende-se refletir sobre alguns dos pressupostos que têm norteado as etnografias dos mercados financeiros, em particular sobre a relação mutuamente constitutiva entre qualidades e quantidades avançada por Latour e Lépinay (2009) e o carácter ontológico da informação visualizada nos monitores (ecrãs). Mais precisamente, este artigo procura averiguar em que medida o grande colapso financeiro de setembro de 2008 terá introduzido elementos novos no enquadramento sociotécnico dos mercados que convidam a pôr em causa os pressupostos enunciados. Para esse efeito, recorrer-se-á a dois tipos de fontes empíricas associadas a momentos agitados da finança global: os dados etnográficos da atividade numa sala de mercados durante o período que envolveu a falência do banco norte-americano Lehman Brothers, precisamente em setembro de 2008, e os consequentes esforços de reforma financeira que se seguiram; em especial os que se centraram nos índices financeiros após o escândalo em torno da manipulação da taxa Libor, em junho de 2012. A ideia mais geral é que se poderá ter passado de uma fase de otimismo quantitativo e negociação pujante para uma fase de ceticismo e descrença, em que a negociação se afigura mais intermitente - restando saber se estaremos 
perante uma transição histórica de amplitude considerável, como parecem sugerir algumas análises recentes da antropologia do dinheiro (GRAEBER, 2011; HART; ORTIZ, 2013), ou se a realidade dos mercados financeiros compreende outras oscilações cíclicas para além das euforias e depressões simbolizadas pelas figuras do touro e do urso...

A informação empírica que sustenta o presente artigo foi recolhida durante a realização de um trabalho de campo em dois bancos comerciais portugueses, entre 2008 e 2009. Esse conteúdo de natureza etnográfica será complementado com dados provenientes de uma pesquisa documental sobre os processos de reforma financeira após a crise de 2008 e o acompanhamento de uma série de consultas públicas internacionais sobre índices financeiros entre 2012 e 2013 - tendo em conta os materiais textuais e audiovisuais disponíveis na Internet e envolvendo também alguma observação participante. ${ }^{1}$

Na próxima seção, apresento uma descrição mais generalista do modo como os mercados financeiros globais são vistos a partir de uma sala de mercados, dando especial atenção ao tipo de informação aí veiculada e à maneira como ela reflete determinadas emoções. Nesta base, serão delineados os contornos de uma epistemologia local que tende a olhar para o mercado como uma realidade objetiva ou objetivável, que funciona segundo uma lógica compatível com as decisões racionais de milhares de agentes espalhados pelo mundo. Trata-se, no entanto, de uma epistemologia em estado crítico, cujos pressupostos racionalistas se veem com frequência ultrapassados pelos acontecimentos. Isto mesmo se tornará claro na segunda seção do texto, largamente composta por uma descrição pormenorizada da atividade situada de um trader (isto é, de um corretor encarregado de negociar determinado tipo de ativos financeiros a partir de uma sala de mercados) ao longo de cerca de hora e meia. A terceira secção considerará o modo como os índices financeiros passaram a ser encarados depois do escândalo da taxa Libor (em 2012), num contexto de reforma financeira de âmbito mundial marcado por uma crescente descrença dos reguladores

\footnotetext{
1 Aproveito para agradecer aos dois bancos portugueses e aos seus colaboradores pelas excelentes condições de investigação que me proporcionaram. Todo o meu trabalho em torno das questões financeiras não teria sido possível sem o apoio da Fundação para a Ciência e a Tecnologia (FCT), através da atribuição de duas bolsas de pós-doutoramento (RSFRH / BPD / 37785 / 2007 e SFRH / BPD / 78438 / 2011) e do financiamento do projeto estratégico da minha instituição, o SOCIUS-ISEG (PEst-OE / SADG / UI0428 / 2013).
} 
face às suas capacidades para lidarem com os riscos sistêmicos. O artigo conclui com uma reflexão sobre os possíveis contributos dessa etnografia para o estudo antropológico das emoções.

\section{Emoções nos mercados financeiros globais: da lógica reflexa à etiologia}

As salas de mercados ou de negociação são repartições bancárias onde o dinheiro disponível nos bancos é investido em diversos mercados financeiros - como o mercado cambial, o mercado de obrigações, o mercado de ações, o mercado de derivados financeiros (em especial os futuros e as opções) ou o mercado monetário interbancário. É igualmente através das suas salas de mercados que os bancos negociam tomadas e cedências com a autoridade central responsável pela moeda em curso, ou seja, no caso dos países membros do Euro, o Banco Central Europeu. Essas salas de mercados foram introduzidas nos bancos portugueses a partir de meados dos anos 1990, impulsionadas pelo investimento crescente em torno dos derivados financeiros e pela sincronização global das bolsas proporcionada pela informatização das plataformas de negociação (cf. KNORR-CETINA; BRUEGGER, 2002a). Hoje em dia, as salas de mercados são uma componente indispensável em qualquer banco comercial, funcionando como front office dos departamentos financeiros.

Na sala de mercados onde efetuei o meu trabalho de campo trabalhavam seis pessoas em secretárias dispostas em $\mathrm{U}$, cada uma delas controlando três a cinco de computador, dois a três teclados e uma central . A divisão continha ainda um televisor permanentemente sintonizado no canal noticioso Bloomberg. Monitores de computador, telefones e a própria televisão surgiam assim como as principais fontes de informação usadas pelos traders. A informação recebida era largamente composta por gráficos e tabelas resumindo dados quantitativos sobre mercados financeiros, bem como por textos de notícias e comentários especializados. Os índices relativos aos mercados de ações e de obrigações apresentavam-se em gráficos de linhas fornecidos pela agência Bloomberg, cuja frequência de atualização era regulável de acordo com intervalos que podiam ir do tempo real (informação renovada ao segundo) até um ano ou mesmo mais (vide Figura 1). 
Figura 1 - O índice Dow Jones no dia 4 de setembro de 2008, conforme gráfico da agência Bloomberg acessível a partir da sala de mercados (intervalos de quinze minutos).

INDU $\uparrow 11285.86-247.02$ i

At $16: 37$ op 11532.48 Hi 11532.48 i Lo 11264.20 i Prev 11532.88

1-DAY CHART INOU - DOW JONES INOUS. AVG 14:30-21:15 USD

Index $\mathbf{G} \mathbf{I P}$

Hi11532.5 Lo11264.2 0p11532.5 \#Ticks 3657 16:37 T11285 - 9

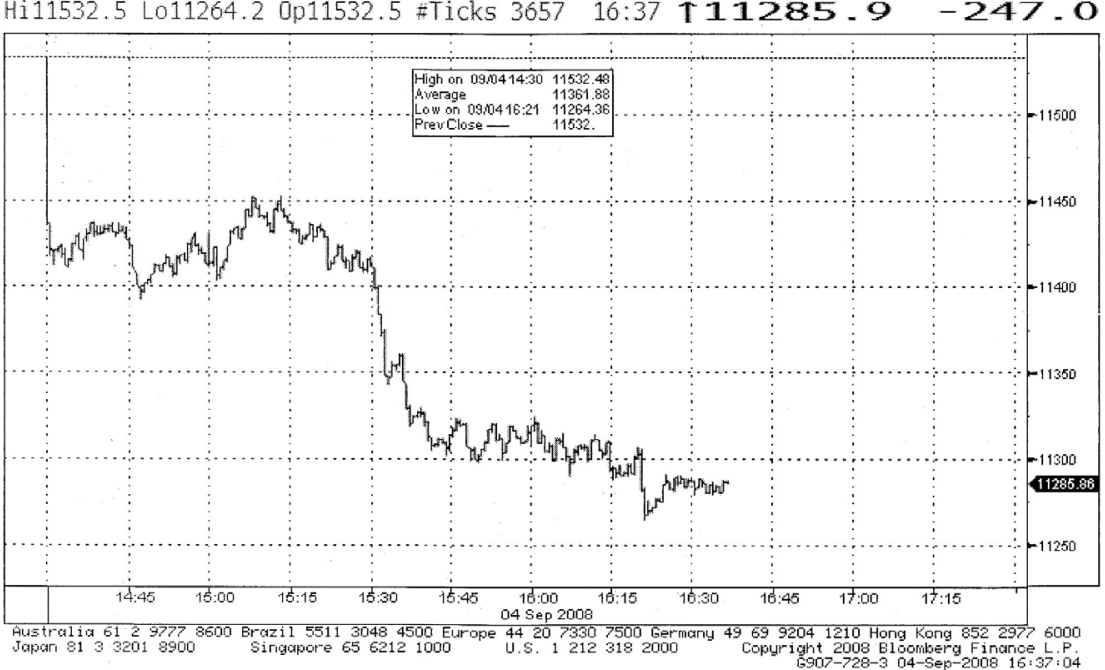

Fonte: Agência Bloomberg.

Desde os meus primeiros dias como observador participante tornouse evidente que as emoções faziam parte dos mercados, manifestando-se muito claramente ao nível desses indicadores mais técnicos. Por exemplo, os índices que descreviam a evolução da contratação de credit default swaps - uma classe particular de derivados implicando a permuta de incumprimentos de crédito - foram-me apresentados como "indicadores de medo", no sentido em que assinalavam o receio sentido pelos atores de mercado em relação à vulnerabilidade financeira de determinadas empresas, sendo frequentemente consultados por traders especializados em produtos de dívida. Outros índices financeiros pareciam ter a mesma capacidade de exprimir as emoções do mercado, por vezes de modo bastante explícito: era o caso dos índices de confiança dos consumidores, mas também das taxas de desemprego ou dos índices imobiliários relativos à construção e venda de casas. $\mathrm{O}$ índice de volatilidade VIX era igualmente visto pelos traders como um indicador de pânico, embora a sua fiabilidade fosse cada vez mais questionável nas semanas de agosto e setembro de 2008. 
Entre a vasta panóplia de índices financeiros, alguns sobressaíam pela sua centralidade. De um modo geral, os índices de ações prevaleciam sobre os índices de obrigações e, entre os primeiros, o índice Dow Jones - que mede o investimento em empresas cotadas na bolsa de Nova Iorque sobrepunha-se a todos os outros: as suas oscilações davam o tom para o comportamento das restantes praças financeiras a nível mundial. Em certas ocasiões, os mercados ficavam como que em suspenso, aguardando a abertura das negociações em Nova Iorque - que, devido aos fusos horários, ocorria com um defasamento de cinco a seis horas face às bolsas europeias - e desejando que o rumo das negociações em Wall Street ajudasse a definir uma tendência. $\mathrm{O}$ próprio investimento em ações era genericamente visto como um sinal de otimismo, implicando retornos mais elevados, mas igualmente um risco maior em caso de desvalorização, opondo-se caso ao investimento em dívida soberana ou de empresas, cujos rendimentos eram fixos, mas bastante mais modestos. Capital e dívida surgiam assim como duas áreas complementares e inversamente proporcionais, aceitando-se que, quando o investimento em ações e índices bolsistas aumentava, o investimento em obrigações e taxas de juro diminuía - e vice-versa. Por essa razão, os índices que davam conta do rendimento das obrigações também eram vistos como "indicadores de medo": entendia-se que qualquer decréscimo do rendimento obrigacionista decorrente de um aumento da procura significava também um receio crescente diante do investimento em ações.

Em relação ao modo como os índices financeiros eram encarados pelos traders, há, portanto, duas ideias a reter: a primeira é a de que os índices refletiam as disposições de um coletivo desconforme, instável e de âmbito global que levava o nome de "mercado" (o mercado de ações, o mercado de obrigações, etc.), revelando a maior ou menor propensão dos investidores para arriscarem o seu dinheiro; a segunda ideia a reter é a de que os diversos tipos de índices se complementavam, funcionando muitas vezes segundo uma lógica de inversão proporcional em que as descidas num setor deviam ser necessariamente compensadas com subidas no setor oposto - mais ou menos de acordo com as premissas de um mercado autorregulador.

Para além dos indicadores de natureza quantitativa, os traders apoiavamse muito em informação de natureza textual, como comunicados oficiais, notícias de divulgação geral e ainda conselhos e comentários especializados de analistas e brokers. Foi-me dito que, em tempos de menor liquidez (i.e. quando havia menos dinheiro a circular, como era o caso no verão de 2008), as 
notícias eram mesmo preferíveis a certos indicadores de análise técnica que se limitavam a fazer projeções estatísticas. A iminência de um colapso bolsista estava então muito presente e transparecia igualmente na dependência dos mercados diante da divulgação oficial de dados econômicos ou ao teor das conferências de imprensa dos governadores dos bancos centrais. Em tais ocasiões, sobrevinha também aquela impressão de suspensão do mercado, como se os investidores dispersos pelo globo aguardassem um sinal que lhes indicasse o rumo a tomar. E, no meio de todo o nervosismo e turbulência que antecederam a queda no abismo, as palavras mereciam, de fato, uma consideração especial. Cientes do efeito performativo dos seus comunicados - ou daquilo que Robert Merton (1948) chamava "profecias autorrealizáveis" e o antropólogo Douglas Holmes (2009) designa como "uma economia de palavras" - , as personalidades mais relevantes do mundo financeiro mediam cuidadosamente os termos que usavam, procurando com isso acalmar os mercados e evitar a propagação do receio. Esse era, porém, apenas um de muitos planos discursivos em jogo. Noutra frente, analistas e comentadores usavam de um tom mais desabrido para dar conta do que se passava. Entre os comentários diariamente enviados para a sala de mercados por um analista do banco Citigroup contavamse expressões como: Fear and panic continue to dominate - I come back to the markets deeper into the unknown than pre-August - The world is coming to an end. Ou seja, enquanto, no plano oficial, a preocupação parecia ser a de serenar os ânimos, num plano oficioso e também mais próximo da prática situada da negociação era a impulsividade que dava o tom.

A lógica dos reflexos mantinha-se no meio desse equilíbrio instável: na sala de mercados onde efetuei trabalho de campo, esperava-se que os comunicados e notícias oficiais e até mesmo os comentários mais restritos de alguns brokers se espelhassem, assim que processados pelos investidores, nos índices financeiros. No caso das conferências de imprensa e comunicados oficiais, o efeito era suposto ser quase imediato - o que também diz muito acerca da efetiva sincronização dos mercados eletrônicos. Por exemplo, assim que o presidente do Banco Central Europeu anunciava que não iria baixar as taxas de juro, os traders desinteressavam-se da conferência de imprensa ainda em curso e concentravam-se em perceber os reflexos daquela decisão na evolução dos gráficos em tempo real.

As lógicas do reflexo e da inversão proporcional têm, no entanto, as suas limitações. Em primeiro lugar, porque nem sempre é possível antecipar aqueles acontecimentos passíveis de afetar visivelmente os mercados e, 
portanto, fazer a devida associação em tempo útil: como tal, os traders eram regularmente confrontados com movimentos significativos nos gráficos sem conseguirem relacioná-los com uma determinada causa. Em segundo lugar, porque a própria instabilidade também acarreta convulsões enigmáticas e, principalmente, uma maior vulnerabilidade aos rumores que circulavam rapidamente pelo espaço virtual. Nesses meses conturbados de agosto e setembro de 2008, a inconstância era tal que os mercados continuavam a descer mesmo após a publicação de dados positivos. Ou então, oscilavam loucamente ao sabor de notícias fortuitas e de origem duvidosa. No dia a seguir à falência do banco Lehman Brothers (15 de setembro de 2008), os movimentos do índice Dow Jones eram pura e simplesmente erráticos: em vinte minutos, o gráfico registrou variações de mais de três por cento na sequência de informações que ora apontavam para um possível resgate da seguradora AIG, ora colocavam essa hipótese de parte.

Nestas alturas, um novo impulso se manifestava, de cariz etiológico, visando conhecer e compreender as causas prováveis de qualquer flutuação significativa e, com isso, devolver ao mercado a sua lógica momentaneamente perdida. $\mathrm{O}$ impulso etiológico implicava pesquisas nos feeds de notícias ou pedidos de informação a interlocutores privilegiados (como os brokers que trabalhavam em grandes bancos internacionais). Relembro o dia em que uma desvalorização abrupta da moeda sueca foi detetada nos gráficos exibidos na sala de mercados. A pessoa responsável pelo trading em mercados cambiais pediu então a um colega que procurasse alguma explicação para isto nos terminais de notícias. Ao fim de poucos minutos, o colega avançou a hipótese de tal movimento constituir uma reação à divulgação de dados oficiais sobre a inflação na Suécia: após ter comparado o momento de difusão da notícia no terminal Bloomberg com o início da desvalorização no gráfico que retratava o investimento na coroa sueca, ele admitiu como provável a relação entre ambos. Esse exemplo não deve, porém, levar-nos a pensar que o estabelecimento de relações de causalidade a posteriori é quase sempre uma tarefa fácil e consequente. O que importa reter, antes de mais, é a presença do impulso etiológico (mesmo que ele se revele inconsequente) e a vontade subjacente de reenviar o funcionamento do mercado para princípios consentâneos com os ideais da autorregulação, onde o que se perde de um lado se ganha do outro.

Muitas vezes, porém, não era fácil descobrir uma explicação para determinados movimentos dos gráficos. Admitia-se então, nestes casos, que o mercado tivesse sido desviado dos seus parâmetros eficientes 
e racionais por rumores, boatos e outros ruídos. O impulso etiológico mantinha-se por conseguinte desperto, como forma de distinguir os movimentos que pudessem legitimar a abertura ou manutenção de uma determinada estratégia de investimento dos chamados "movimentos de manada" decorrentes do pânico ou de outras emoções descontroladas. Continuava a fazer sentido, em suma, acreditar na viabilidade de um mercado autorregulador alicerçado nas escolhas racionais e logicamente complementares das diversas contrapartes que o compunham - um mercado emocionalmente controlado, adequável aos preceitos da etnopsicologia ocidental moderna (cf. REZENDE; COELHO, 2010, p.104-111) e, por isso mesmo, um mercado amigo dos investidores. Mas essa era apenas a parte boa da história. A verdade é que, no verão de 2008, esse mercado era pouco mais que uma miragem, um sonho. $\mathrm{O}$ equilíbrio entre as contrapartes era visto como instável: o medo, a desconfiança, o nervosismo, a precipitação manifestavam-se regularmente não só nos corpos e na voz dos traders como igualmente nos gráficos e comentários apresentados nos ecrãs; o que nos leva a procurar descrever mais pormenorizadamente o modo como são vividas e geridas as emoções dentro de uma sala de mercados.

\section{"Vela no Bund!", ou um dia na vida de um trader}

Não pretendo que as descrições aqui apresentadas sejam largamente generalizáveis. Já antes aludi às peculiaridades do contexto etnográfico em apreço - nomeadamente à pequena dimensão da sala de mercados onde efetuei trabalho de campo, a que se deve juntar a relativa insignificância dos bancos comerciais portugueses enquanto atores do sistema financeiro global. O banco de que tenho vindo a falar estava apenas marginalmente exposto às convulsões que assolaram a bolsa de Nova Iorque em setembro de 2008 e, por outro lado, dispunha igualmente da possibilidade de se financiar através da captação de depósitos de clientes (algo que os grandes bancos de investimento internacionais como o Lehman Brothers não podiam fazer). Como tal, esse banco foi sobretudo um observador e, portanto, também um bom posto de observação - ainda que nenhuma instituição financeira esteja completamente a salvo num sistema que favorece a criação de dinheiro com base em reservas fracionadas. Na secção anterior procurei descrever o modo como os mercados financeiros se apresentavam na sala de mercados. Como foi dado a entender, esses mercados exibidos nos ecrãs 
de computadores podem ser vistos como a expressão agregada, estatística, quantitativa, de comportamentos que ocorrem simultaneamente em arenas de negociação de todo o mundo (por mais pequenas e insignificantes que sejam...). Olhemos com mais atenção para o desenrolar da ação dentro de uma sala de mercados e, em particular, para o lugar que aí ocupam as emoções...

Nas páginas que se seguem, apresento um excerto do meu diário de campo, onde se descreve a atividade de um trader durante cerca de hora e meia, com alterações e excisões mínimas destinadas a proteger o anonimato tanto da instituição como das pessoas envolvidas. Porém, manter-se-á o nome real das principais empresas de informação financeira e dos grandes bancos internacionais que acabaram por ter um papel de relevo no auge da crise de 2008, sempre que tal pareça etnograficamente relevante e em linha com a informação anteriormente avançada. A fim de tornar a leitura mais percetível, impõem-se dois esclarecimentos adicionais. O primeiro esclarecimento diz respeito ao tipo de operação financeira em jogo - a negociação de contratos de futuro sobre dívida soberana da Alemanha com prazo de dez anos. À semelhança de outros derivados financeiros, os contratos de futuro não pressupõem a compra ou venda direta do ativo subjacente (ou seja, as obrigações soberanas, conhecidas no meio financeiro pela expressão alemã Bund), mas a compra ou venda de promessas de compra ou venda futuras desse mesmo ativo, de acordo com prazos previamente estipulados, e que podem ser de três, seis ou doze meses, por exemplo. Não obstante, os traders designam muitas vezes as suas operações de derivados com o nome do ativo a que se reportam, pelo que, no excerto seguinte, as menções ao Bund devem ser entendidas como 'operações de futuros sobre o Bund'. O segundo esclarecimento é, na verdade, uma insistência, para vincar o fato de os atores menores do sistema financeiro global, como o banco aqui em causa, recorrerem constantemente aos serviços de empresas de informação econômica, como a Bloomberg ou a Thomson Reuters, bem como de corretoras e grandes bancos internacionais (é o caso do Citigroup, mencionado anteriormente), no sentido de compreenderem melhor e participarem no que se vai passando nos mercados globais. Posto isto, entremos então na sala de mercados...

"São 15h44. Sento-me junto de Mário, o trader de negociar com obrigações e taxas de juro. Ele consulta os ecrãs do terminal Bloomberg e vai tomando notas sobre 'coisas que gostaria de fazer, 
se não fosse de férias' [Mário partiria em breve em lua de mel]. Mas eis que a voz do diretor se faz ouvir, vinda do seu posto onde ele vai seguindo a evolução dos vários mercados:

- Vela no Bund!

Num primeiro instante, Mário dá a entender que está a controlar a situação. Porém, um minuto depois, o diretor volta a intervir e a sua voz trai alguma preocupação:

-Atenção! Alguma coisa está a acontecer!

Desta vez não há dúvidas: num dos ecrãs à frente de Mário, o gráfico com a evolução em tempo real da negociação de futuros sobre o Bund desenha a forma característica de uma vela, sinalizando neste caso uma descida abrupta de mais de 30 pontos básicos" (vide figura 2).

Figura 2 - A evolução da negociação de futuros sobre o Bund (dívida soberana alemã com prazo de dez anos), segundo gráfico fornecido pela agência Bloomberg. O movimento de descida identificado como uma "vela" ocorreu pouco antes das 16 horas e está assinalado com um círculo.

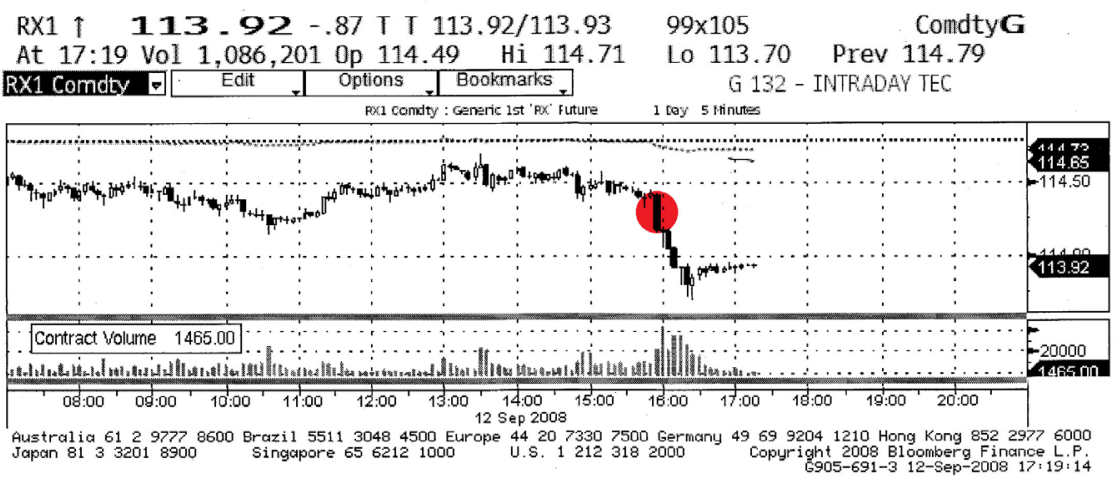

"Através da sala de chat da Bloomberg, Mário redige uma mensagem para James, um broker do Citigroup com quem está em contato permanente: '- any news on bund?'. Bastante concentrado, batendo nas teclas do computador a toda a velocidade, Mário consulta uma lista de notícias no terminal Bloomberg, constatando que 'está a sair muita coisa'. O instante é vivido com alguma tensão, contrastando claramente com a calmaria de há momentos. À sala de chat chega uma primeira resposta proveniente do Citigroup, um minuto depois de Mário ter enviado a sua mensagem: '- not sure... sec'. Nove segundos depois, uma segunda mensagem: '- we are still unsure, maybe the bounce in bank stocks?'. 
A sugestão do broker, formulada em jeito de pergunta, não convence Mário. Ele levanta-se e vai ter com o diretor, transmitindo-lhe a sua opinião:

'-O James diz que houve aqui alguém a fazer um bounce brutal em Euribor [i.e. um investimento forte em futuros indexados à taxa de juro Euribor]: 86 mil contratos em Euribor. Mas a Euribor, por norma, não tem ligação direta com Bund... Eles [Citigroup] estão a tentar averiguar, acham que pode ter a ver com as financeiras. Mas eu já estive a ver e... Eu não sei o que está por trás disto. Este tipo de movimentos faz-me um bocado de confusão... e, como tal, estou tentado a fechar a posição...'.

Mário retoma o seu lugar e observa o gráfico com a evolução dos futuros sobre o Bund. A queda acentua-se. O diretor, que continua a supervisionar os acontecimentos a partir do seu posto, confirma que se trata de uma variação muito grande. Mário responde, com algum alarme na voz:

'- Isto é à volta de quarenta [pontos] básicos em menos de quatro minutos! Eu vou fechar isto! Isto não pode ficar aberto mais tempo!'.

E começa a preparar a sua saída do mercado, mexendo no rato ligado à plataforma de derivados:

'-Eu vou levar uma bordoada de todo o tamanho!'.

No gráfico, o indicador do preço de cedência do Bund (Bid Price) desceu para 113.85, coincidindo com o momento de maior aflição. Segundos depois, sobe ligeiramente para 113.88 [tratase de números meramente indicativos e que não correspondem a nenhum preço exprimível numa unidade monetária]. Mário ainda não fechou a posição. Redige nova mensagem para o broker do Citigroup: '- leh keeps losing some $10 \%$ and AIG 20\%...'. Isto é, o Lehman Brothers está a cair em bolsa, assim como a seguradora AIG, pelo que não se compreende a razão da queda do Bund [de acordo com a lógica da inversão proporcional, quando as ações descem, as obrigações tendem a subir...]. O diretor pergunta a Mário se 'já fechou' e este responde que : '- não, ele entretanto voltou a subir [de 113.85 para 113.88]. Mas, se voltar a cair nos 85 [113.85], fecho'. A tensão mantém-se, portanto.

Pouco depois, o indicador do preço dos futuros sobre o Bund resvala para 113.82. O momento não é para brincadeiras. Às 16h21, Mário fecha a posição em 113.76... 1.34 pontos abaixo do preço de abertura e 0.09 ponto abaixo dos 113.85 prometidos há instantes ao seu diretor. Os gráficos relativos aos futuros sobre o Bund registram uma queda pronunciada. Às 16h22, o broker do Citigroup responde à mensagem anterior de Mário: '- Equities rebounded sharply, putting F1 lower as story going the rounds that 
Bank of America winning race to buy Lehmans...'. Mário agradece ('tks'), mas confessa que esta explicação - que alude a um efeito de ricochete no mercado de ações motivado pela possível compra do Lehman Brothers pelo Bank of America, e que também provocou uma descida no rating das obrigações - não o satisfaz. Uma pesquisa rápida no terminal Bloomberg permite perceber que o banco Lehman Brothers continua a perder em bolsa. Nesse momento, a colega do lado pergunta-lhe se já sabe alguma coisa. Mário diz que não encontra nada e que no Citigroup também não sabem nada... E dá um murro na mesa, em sinal de impaciência: '- Porcaria de boatos da treta!'.

Às 16h27, nova mensagem do broker do Citigroup, propondo outra explicação para a desvalorização dos futuros sobre a dívida soberana alemã: '- some other talk of CTA's heavy selling on Bund after technical points hit on dma's'. '- Já acredito mais nesta', diz Mário à mesma colega, 'venda maciça de Bund com base em análise técnica'.

O diretor da Sala de Mercados termina um telefonema e pergunta a Mário 'o que é que fez'. Este responde que : '- fechei o Bund a 76 [113.76]. Agora está-me a dar vontade de entrar com cinquenta longos [isto é, abrir uma posição correspondente a cinquenta contratos de compra (futura) de obrigações, tirando partido da desvalorização]. Já não digo nada...'. Mário vira-se para o ecrã da plataforma de derivados, pega no mouse e começa a preparar uma nova posição de 50 contratos de compra sobre as obrigações Bund: coloca o ponteiro do mouse em cima de um botão virtual com a expressão BUY e aguarda. São agora 16h31. Mário mantém a sua decisão de entrar, mas ajusta o preço de 113.85 para 113.89 , depois para 113.91, depois para 113.90 - são modificações aparentemente mínimas mas que podem ter implicações significativas em termos de ganhos e perdas. Volta a colocar o ponteiro sobre o botão BUY e espera, de indicador em riste, pronto a clicar no mouse. Provavelmente, não se sente muito seguro, dado que se levanta e vai ter com o diretor. Diz-lhe que está a pensar em entrar com cinquenta contratos de compra e acrescenta que 'já temos duas explicações, uma em que não acredito [rumor de compra do Lehman Brothers pelo Bank of America] e outra de análise técnica'. Mário regressa ao seu lugar, volta a pegar no mouse, coloca o ponteiro sobre a opção BUY, depois altera o preço para 113.92. Às 16h34, entra no mercado com 50 contratos de compra sobre o Bund a 113.92 .

Pouco depois, Mário começa a preparar uma posição de saída, a 113.94 - como se percebe, é em torno de pequenas margens como esta (uma diferença de 0.02 entre a entrada e a saída) que se 
faz o negócio do trading. Por volta desta altura, aparecem na sala duas colegas de outro departamento da direção financeira para se despedirem de Mário, desejando-lhe felicidades para o casamento e uma boa lua-de-mel. Ele agradece, mas praticamente não desvia os olhos dos ecrãs. Decorrem mais uns minutos. Mário afina o preço de saída da posição, situando-o agora na casa dos 114.12. $\mathrm{O}$ diretor da sala de mercados diz que vai ter que se ausentar e pergunta a Mário se está a pensar sair cedo. Este informa que 'está longo sobre o Bund' e diz que, quando sair, será provavelmente 'para o hospital'. O diretor retira-se. São 16h48. Mário passa as mãos pela cabeça e solta novo desabafo, em voz mais baixa, como que falando consigo próprio, lamentando a decisão de reentrar no mercado logo após ter saído:

'-Que estupidez, caraças!'

16h50: preços e gráfico mantêm-se estáveis, sem terem 'feito nada de extraordinário'. 16h53: Mário atende um telefonema, que depois passa à colega do lado. Volta a dirigir a sua atenção para os ecrãs, esperando ansiosamente que os gráficos das ações caiam para ver se os gráficos das obrigações começam a subir. $\mathrm{O}$ indicador do preço dos futuros sobre o Bund anda à volta dos 113.92, a ordem de saída continua nos 114.12. Por momentos, o preço sobe até aos 113.95, mas depois volta a descer. Mário acompanha atentamente todas estas oscilações e volta a afinar o preço de saída, situando-o agora nos 114.05. Em seguida, dá a ordem de venda, que fica com o estatuto pendente ('working') na plataforma. Tomada a decisão, ele confidencia-me sentir algum medo em relação ao preço 114.00 - um número certo, redondo, que funciona como uma 'resistência natural', revelando-se o alvo preferencial de muitas apostas para fecho de posições.

A partir das 17h06, Mário fica só na sala de mercados. O ambiente de maior tensão já passou, as decisões estão tomadas, resta esperar pela evolução dos acontecimentos. Aproveitamos então para conversar um pouco. Mário diz-me que se sofre um bocado na posição de trader. Apesar de não ser o dinheiro dele que está em jogo, é o dinheiro da instituição que lhe paga e isso induz um grande sentido de responsabilidade. Por outro lado, a instabilidade dos mercados também não ajuda:

'- Nós temos passado o ano todo a rever as coisas. Existem determinados pressupostos que são válidos por um tempo muito curto'.

Alude depois à opinião de um analista que escutou num podcast, dizendo que esta crise é como uma tempestade perfeita que surgiu do meio do céu azul e agora não há forma de lhe escapar:

'- É muito, muito difícil manobrar num ambiente destes. Hoje 
saíram dados macroeconómicos importantes nos Estados Unidos e os mercados não reagiram. Só reagiram aos boatos. É complicado...'.

E conclui a sua reflexão com uma sentença:

'- O mercado é nosso amigo. Nós é que não sabemos compreendê-lo'. ".

Esse excerto, necessariamente longo, permite reforçar alguns princípios que enquadram a ação numa sala de mercados, dando especial atenção ao modo como aí são experienciadas as emoções. Os gráficos e indicadores financeiros apresentados nos ecrãs são a fonte de informação primordial. Em momento algum se coloca em causa a capacidade dos gráficos e índices para espelharem adequadamente o mercado - em bom rigor, a realidade do mercado consubstancia-se neles. O que se passa é que nem sempre é possível compreender os movimentos do mercado. O esforço etiológico assinala então a busca de um sentido, de uma narrativa ou história que permita atribuir uma motivação clara, lógica, para as subidas e descidas mais bruscas conhecidas no meio como "velas". Ora, no período em causa, que rodeou uma das maiores crises financeiras da era moderna, esse esforço de compreensão era muitas vezes infrutífero. $\mathrm{O}$ mercado projetado nos ecrãs mais parecia um monstro desenfreado, presa fácil de hesitações e precipitações incentivadas por "boatos" sem fundamento.

Mas aquilo que os ecrãs agregam, calculam e sintetizam graficamente surge de forma mais dispersa na mente e nos corpos dos traders espalhados pelas plataformas de negociação do mundo inteiro. Algumas etnografias realizadas em megabancos de investimento descrevem o trading como uma atividade bastante individualista, psicologicamente exigente, entusiasmante ou mesmo viciante e também, por tudo isso, potencialmente destruidora do self (KNORR-CETINA; BRUEGGER, 2002b, p.939-940; ZALOOM, 2006). $\mathrm{O}$ medo de ser arrastado numa onda de desvalorização de ativos (como a "vela no Bund" descrita mais acima) e a hesitação quanto à iminência dessa onda de desvalorização são sensações mais ou menos onipresentes. Em condições de estabilidade geral dos mercados, os traders dispõem mesmo de uma margem considerável para desafiar o medo e testar limites pessoais, o que aproxima o seu trabalho de outras atividades envolvendo um jogo com o perigo ou uma tensão entre seriedade e brincadeira - dos desportos radicais (ROCHA, 2011) à pilotagem de aviões de combate (ZALOOM, 2003, p.269). Nas alturas de crise, porém, os dispositivos de controle de emoções são desarmados, fazendo com que a aura de jogo se desvaneça e o pânico 
ameace tornar-se galopante - dependendo, claro, da maior ou menor exposição aos movimentos de desvalorização. Na descrição apresentada, essa exposição era mínima: o trader manifestava algum desconforto pelo fato de ter causado um prejuízo pontual ao banco, sentindo igualmente frustração pela impossibilidade de negociar no meio de tanta turbulência. O seu nervosismo e o seu medo eram, apesar de tudo, bastante suaves, tendo em conta o ambiente sentido em muitos bancos à beira da falência ou prestes a ser resgatados. Embora os dados de que disponho não sejam conclusivos, dado que as poucas etnografias de salas de mercados dão conta do período mais otimista que antecedeu a crise, uma coisa parece mesmo assim evidente a respeito do contexto que conheci: a preocupação de socializar a incerteza e o próprio medo tanto através de discussões com colegas como da conversa online com os brokers. Voltarei a esse aspeto na conclusão, uma vez que ele permite introduzir algumas variações na compreensão da ação situada em salas de mercados.

\section{0 fim de uma era?}

As descrições apresentadas até ao momento dizem respeito a um período que, não obstante todo o receio e nervosismo diante da crise iminente, é ainda um período de confiança nos indicadores financeiros que dão visibilidade à realidade dos mercados, por mais instável e volúvel que essa realidade pareça. Ou seja, a relação mutuamente constitutiva entre a quantidade (índices e gráficos) e a qualidade (o mercado e os movimentos emocionais que o caracterizam) mantém-se. Ninguém na sala de mercados punha em causa que as oscilações registradas nos gráficos constituíam o mercado propriamente dito - mesmo se já não se tratava do mercado autorregulador sonhado por Hayek e outros arautos do neoliberalismo.

Há, no entanto, algumas razões para pensar que essa visão do mundo começa a se alterar. O esforço de reforma financeira global iniciado em 2009 trouxe consigo um conjunto de novas instituições (como o Financial Stability Board ou o Sistema Europeu de Supervisão Financeira) e de acordos internacionais (Basileia III), a que se tem juntado uma série apreciável de princípios normativos. Por outro lado, esse esforço parece ter trazido também mais ceticismo e descrença quanto à possibilidade de reformar efetivamente um sistema financeiro cuja estabilidade depende, em larga medida, de megabancos internacionais com caráter sistêmico 
que se revelam instituições excessivamente complexas e insuficientemente sólidas - ou insuficientemente líquidas, dado que a falta de solidez bancária passa muitas vezes por problemas de liquidez... Não me refiro, é claro, ao ceticismo crônico de jornalistas e cientistas sociais (vide ADMATI; HELLWIG, 2013; LANCHESTER, 2013a e 2013b), mas ao ceticismo de figuras oficiais do próprio sistema financeiro mundial - como o antigo presidente do Fundo Monetário Internacional, Dominique Strauss-Kahn, que deu a conhecer as suas dúvidas e incertezas numa conferência de imprensa de outubro de 20102; ou o ex-governador do Banco da Inglaterra, Mervyin King (2013, p.6, citado por LANCHESTER, 2013b), que declarou ser preciso esperar uma geração para ver resolvidos os problemas sistêmicos colocados pelos grandes bancos globais. O sentimento de impotência dos reguladores financeiros é igualmente o mote de um artigo recente de Annelise Riles (2013), dando conta do ambiente no Banco do Japão no período que se seguiu ao acidente nuclear de Fukushima.

De resto, o fato de as perturbações no mundo financeiro não terem exatamente terminado após o colapso bolsista de setembro de 2008 contribuiu para agravar esse estado de coisas. Em meados de 2012, quando a Europa se debatia com a denominada "crise do Euro" (ou o decréscimo de confiança na moeda única em consequência do sobre-endividamento de países-membros, como a Grécia, a Irlanda, Portugal, Espanha ou Itália,) rebentou no Reino Unido o escândalo em torno da manipulação da taxa de juros Libor. Não será exagero dizer que a Libor (ou London Interbank Offered Rate) é uma das séries de números mais consequentes em todo o mundo (cf. MACKENZIE, 2009, p.1). Em termos técnicos, a Libor representa os custos de financiamento incorridos por um painel de megabancos no que toca à constituição de fundos em dólares (bem como noutras moedas) com prazos que vão de uma semana até um ano. Em termos práticos, trata-se da taxa de juros que serve de referência às demais taxas de juros, sendo igualmente utilizada como indicador numa quantidade impressionante de contratos de derivados financeiros.

O cálculo da Libor é efetuado pela empresa Thomson Reuters, com base nas estimativas de taxas fornecidas pelos bancos membros do painel. Ora,

\footnotetext{
${ }^{2}$ Disponível em: http://www.imf.org/external/np/tr/2010/tr100710.htm. Acesso em 25 de agosto de 2013.
} 
em 2009, uma investigação internacional liderada pela Financial Services Authority descobriu indícios claros de manipulação de dados no processo de submissão de informação conducente ao cálculo da taxa: alguns dos bancos do painel estariam a fornecer valores de taxas muito distantes dos seus custos de financiamento efetivos, com o objetivo de influenciarem a média final e, dessa forma, obterem lucros adicionais em operações especulativas indexadas à Libor (cf. WHEATLEY et al., 2012). Embora os dados da investigação oficial apontassem para práticas de manipulação iniciadas, no mínimo, por volta de 2005, os depoimentos de alguns traders recolhidos por jornalistas no âmbito de investigações paralelas faziam remontar os procedimentos obscuros ao final dos anos 1980 (THE ECONOMIST, 2012) - ou seja, abarcando a quase totalidade da curta história da Libor... As suspeitas estenderam-se rapidamente a outras taxas de referência (como a Euribor), levando à inclusão da manipulação de índices financeiros na Diretiva de Abusos de Mercado da União Europeia, assim como a uma sucessão de debates e consultas públicas sobre indicadores de mercado promovidas por diferentes autoridades nacionais e internacionais. Ao mesmo tempo, no setor privado, várias associações industriais e empresas do ramo procuravam desenvolver princípios e códigos de conduta que pudessem garantir a produção de indicadores fiáveis. O escândalo em torno da manipulação da Libor teve, portanto, o condão de instalar a dúvida quanto à capacidade dos números para representarem adequadamente o mercado, levando atores e reguladores a pensar no que seria preciso fazer para que os índices voltassem a refletir rigorosamente as realidades econômicas que pretendiam medir.

Nesse âmbito, admitiu-se o recurso aos dados de transações efetivas (em vez de meras estimativas) para obter uma percepção mais fiável das operações em curso no mercado. Nas palavras da diretora executiva da nova Autoridade Europeia dos Mercados e Valores Mobiliários (ESMA), Verena Ross, proferidas durante uma audiência pública em Paris, a 13 de fevereiro de 2013: "Deve haver algum teste de realidade entre aquilo que os indicadores dizem e aquilo que as transações dizem". Ross referia-se, em primeiro lugar, às taxas Libor e Euribor que, sob esse aspeto, representavam um caso interessante. É que o mercado que essas taxas deviam supostamente refletir funcionava de modo muito intermitente desde 2008 para os empréstimos com prazo superior a um mês devido a uma série de causas interligadas, que iam da crise das dívidas soberanas europeias e consequente descida dos ratings à influência crescente dos empréstimos dos bancos centrais, sem 
esquecer as novas medidas de controle dos rácios de liquidez propostas pelo Acordo de Basileia III e - inevitavelmente, - o próprio escândalo em torno da taxa Libor. Ou seja, embora os megabancos membros dos painéis da Libor (e Euribor) reportassem diariamente estimativas de custos de financiamento para depósitos de um mês a um ano, a constituição efetiva de tais depósitos era, na melhor das hipóteses, apenas episódica. Como reconhecia o presidente da Commodity Futures Trading Commission durante uma mesa redonda promovida pela IOSCO cerca de duas semanas depois: "- Este é um mundo no qual se pede aos bancos que reportem sobre algo que pode nem sequer existe". E, pensando nas taxas Libor e Euribor com maturidades superiores a trinta dias: "- Quando uma referência não se refere a coisa alguma, o que será que ela é?"3.

Poder-se-ia responder que é uma ficção e não um fato. E que a confiança nos mercados financeiros assenta tradicionalmente em "fatos" - em dados considerados fiáveis, em representações vistas como adequadas e que possam ser aceitas sem discussão para fins de trading e de investimento (cf. MACKENZIE, 2009). Se bem que a tendência, por parte dos reguladores, seja a de fazer o caminho de volta em direção à facticidade, as discussões públicas travadas em torno dessa questão deixam perceber que esse caminho é mais sinuoso do que se poderia pensar à partida. Alguns participantes ligados à indústria dos índices econômicos fizeram notar que, em muitos casos, esses índices contribuem para criar a liquidez de mercado em vez de se limitarem a refleti-la - ou seja, a publicação dos índices permite dar visibilidade a determinados setores da atividade econômica, fornecendo informação agregada, estandardizada e facilmente acessível sobre operações dispersas e, dessa forma, fazendo aumentar o número das transações. Neste sentido, os índices teriam uma capacidade performativa própria, ao definirem antecipadamente um reduto de trocas que, em função dessa definição, se assumiria como um "mercado" e estimularia a negociação. Teríamos primeiro uma quantidade esparsa, depois uma qualidade (uma ideia de mercado agregado refletida num indicador) e, finalmente, um aumento significativo da quantidade com base nessa qualidade - um esquema,

\footnotetext{
3 "This is a world in which banks are being asked to quote something that might not even exist / If the benchmark isn't benchmarking something, then what is it that we have here?". A mesa redonda organizada pela IOSCO teve lugar em Washington, a 26 de fevereiro de 2013. Disponível em: http:/ / www.youtube.com/watch?v=duUODyMdnsE. Acesso em 1 de Junho de 2014.
} 
pelo menos, um pouco mais complexo do que a visão tardiana de Latour e Lépinay exposta no início deste artigo.

Mas, não é tudo. Na sua resposta à consulta pública promovida pela Autoridade Europeia dos Mercados e Valores Mobiliários (ESMA) e pela Autoridade Bancária Europeia (EBA), a Associação Europeia das Cooperativas Bancárias comparou a confiança nos indicadores financeiros à confiança no próprio dinheiro, na medida em que ambas dependiam de arranjos institucionais coletivos apenas parcialmente controláveis por atores de mercado individuais (EUROPEAN ASSOCIATION OF CO-OPERATIVE BANKS, 2013, p.3). Por outras palavras, a produção de fatos, por si só, não garantia nada. Era necessário que várias instituições alinhassem no jogo e aceitassem como válido aquilo que era apresentado como um fato. Um tal acordo coletivo, para além de ser vulnerável a tentativas de manipulação individual, não era nunca suficiente para evitar que instituições saudáveis sucumbissem sob a influência de profecias autorrealizáveis, ou que bancos com caráter sistêmico arrastassem atrás de si todo um mercado incapaz de funcionar de acordo com uma lógica de complementaridades. A história, claro, não acaba aqui, e ainda é cedo para tirar conclusões. De qualquer modo, a situação é de impasse - entre o otimismo quantitativo e a correspondente crença num mercado amigo dos investidores por um lado, e a descrença nas capacidades autorregulatórias do mercado num cenário dominado por megainstituições, cuja reforma é complicada e morosa, por outro.

\section{Conclusão: contextualizando as emoções}

Os dados empíricos oferecidos neste artigo permitem reforçar alguns dos enunciados centrais do estudo antropológico das emoções (vide ABULUGHOD; LUTZ, 1990; REZENDE; COELHO, 2010; COELHO; REZENDE, 2011), em particular no tocante à necessidade de sua contextualização que acarreta, inevitavelmente, um questionamento da pretensa universalidade dos estados emotivos. As descrições da segunda seção permitem perceber a importância que a interação presencial e a socialização das emoções assumem no universo do trading - sobretudo em conjunturas de instabilidade. Nesse contexto, nervosismo e medo aparecem-nos como um complexo de perceções, racionalizações, intenções, reações físicas, interlocuções e colaborações que mobilizam e são mobilizadas tanto por pessoas (próximas 
e distantes) como por uma rede de dispositivos tecnológicos e informativos que projetam e marcam o ritmo da ação. A contextualização é, neste caso, tanto social como técnica, tanto discursiva como ativamente situada, afastando-nos de visões do medo como um estado primário e universal que a neurociência, por exemplo, não conseguiu descartar por completo (vide DAMÁSIO, 2001, p.79).

Mas o fato de a contextualização ser social e técnica, discursiva e reativa, não quer dizer que o seja sempre por igual - havendo ainda que contar com condicionamentos institucionais, nomeadamente uma maior ou menor exposição aos movimentos de desvalorização que pode marcar a diferença entre o mero receio e o medo, até o pânico. Vale a pena lembrar que o relacionamento dos traders com o mercado chegou a ser classificado como "pós-social" por autores tão influentes como Knorr-Cetina e Bruegger (2002c), no intuito de sublinhar os laços construídos entre seres humanos e objetos - designadamente ecrãs de computador - que, em contexto de interação, surgem como seres reflexivos portadores de experiência, sentimento e recordação (Ibid, p.163). As etnografias de Knorr-Cetina e Bruegger enfatizam bastante o lado técnico da atividade negocial e, nesse sentido, podem ser hoje olhadas como emblemáticas de um período dourado do trading, quando os mercados pareciam ser ontologicamente líquidos (Ibid, p.168) e a principal preocupação dos diretores das repartições de investimento era a de controlar a euforia dos seus colaboradores. Esses mercados não desapareceram, como é óbvio. Mais: o extraordinário desenvolvimento, nos últimos anos, do chamado high-frequency trading - ou trading totalmente computorizado (vide MACKENZIE et al., 2012) - pode ser entendido como mais um passo em frente no sentido da póssocialidade. De qualquer modo, em 2007-2008 a interação com os ecrãs tinha-se tornado mais complicada, exigindo a recolha de informação complementar junto de intermediários e uma constante troca de impressões entre colegas. Poder-se-ia, portanto, admitir como hipótese que as emoções positivas do mercado (a esperança e, no limite, a euforia) apontam para a pós-socialidade, enquanto as emoções negativas (a apreensão, o medo...) implicam um regresso a formas mais tradicionais de socialidade laboral. Seja ou não assim, a verdade é que o contexto, nos seus contornos sociais ou técnicos, reflexivos ou ativamente situados, nunca se apresenta como uma realidade estável e, por isso, necessita de ser sempre explicitado. E a etnografia tem, nesse domínio, uma palavra importante a dizer. 


\section{Referências}

ABU-LUGHOD, Lila; LUTZ, Catherine (Orgs.). (1990). Language and the Politics of Emotion. Nova Iorque, Cambridge University Press.

ADMATI, Anat; HELLWIG, Martin.

(2013). The Banker's New Clothes: What's wrong with Banking and What to Do about It. Princeton, Princeton University Press.

COELH0, Maria Claudia; REZENDE, Claudia Barcellos (Orgs.).

(2011). Cultura e Sentimentos: Ensaios em Antropologia das Emoções. Rio de Janeiro, Contra Capa.

DAMÁSI0, António.

(2001 [1999]). 0 Sentimento de Si: 0 Corpo, a Emoção e a Neurobiologia da Consciência. Lisboa, Publicações Europa-América.

DELUMEAU, Jean.

(1989 [1978]). História do Medo no Ocidente, 1300-1800: Uma Cidade Sitiada. São Paulo, Companhia das Letras.

EUROPEAN Association of Co-operative Banks. (2013). European Association of Cooperative Banks Comments on ESMA and EBA Consultation Paper on Principles for Benchmark-Setting Processes in the EU. Disponivel em: http://www.esma.europa.eu/ system/files/2013-02-15_eacb_positions_ to_consultation_on_rate_setting_process. pdf. Acesso em 4 de Junho de 2014.

GRAEBER, David.

(2011). Debt - The First 5,000 Years. New York, Melville House.

HART, Keith; ORTIZ, Horacio. (2013). The Anthropology of Money and Finance: From Ethnography to World History. Disponivel em: The Memory Bank » Blog Archive » The anthropology of money and finance: from ethnography to world history . Acesso em 10 de Agosto de 2014.

HOLMES, Douglas.

(2009). Economy of words. Cultural Anthropology, Vol.24, n.3, p.381-419.
KING, Mervyin.

(2013). Speech: a governor looks back - and forward. London, Bank of England. Disponivel em: http://www.bankofengland.co.uk/ publications/Documents/speeches/2013/ speech670.pdf. Acesso em 4 de Junho de 2014.

KNORR-CETINA, Karin; BRUEGGER, Urs.

(2002a). Inhabiting technology: the global lifeform of financial markets. Current Sociology, vol.50, n.3, p.389-405.

(2002b). Global microstructures: the virtual societies of financial markets. American Journal of Sociology, vol.107, n.4, p.905-950

(2002c). "Traders" engagement with markets: a postsocial relationship. Theory, Culture \& Society, vol. 19, n.5-6, p.161-185.

LANCHESTER, John.

(2013a). Are we having fun yet?. London Review of Books, vol. 35, n.13, p.3-8.

(2013b). Let's consider Kate. London Review of Books, vol.35, n.14, p.3-8.

LATOUR, Bruno.

(2010). Tarde's idea of quantification. In: Matei Candea (Ed.); The Social after Gabriel Tarde: Debates and Assessment. Londres, Routledge. p.147-164.

LATOUR, Bruno; LÉPINAY, Vincent-Antonin.

(2009). The Science of Passionate Interests: an Introduction to Gabriel Tarde's Economic Anthropology. Chicago, Prickly Paradigm Press.

MACKENZIE, Donald.

(2009). Material Markets: How Economic Agents Are Constructed. 0xford, 0xford University Press.

MACKENZIE, Donald; BEUNZA, Daniel; MILLO, Yuval; PARDO-GUERRA, Juan-Pablo.

(2012). Drilling through the Allegheny Mountains: liquidity, materiality and high- 
frequency trading. Journal of Cultural Economy, vol.5, n.3, p.279-296.

MERTON, Robert K.

(1948). The self-fulfilling prophecy. Antioch Review, vol.8, n.2 p.193-210.

REZENDE, Claudia Barcellos; COELH0, Maria Claudia.

(2010). Antropologia das Emoções. Rio de Janeiro, FGV Editora.

RILES, Annelise.

(2013). Market collaboration: finance, culture, and ethnography after Neoliberalism. American Anthropologist, vol.115, n.4, p.555569.

ROCHA, Verônica.

(2011). Ninguém se arrisca à toa: os sentidos da vida para praticantes do exporte base jump. In: Maria Claudia Coelho; Claudia Barcellos Rezende (Orgs.); Cultura e Sentimentos: ensaios em Antropologia das Emoções. Rio de Janeiro, Contra Capa. p.63-80.

The Economist.

(2012). The LIBOR scandal: the rotten heart of finance. Disponivel em: http://www. economist.com/node/21558281. Acesso em 4 de Junho de 2014.
WHEATLEY, Martin (Org.).

(2012). The Wheatley Review of LIBOR: Final Report. Disponivelem:https $\% 3 \mathrm{~A} \% 2 \mathrm{~F} \% 2 \mathrm{Fwww}$. gov.uk\% 2 Fgovernment $\% 2$ Fuploads $\%$ 2 Fsystem $\% 2$ Fuploads $\% 2$ Fattachme nt_data\%2Ffile\%2F191762\%2Fwheatley review_libor_finalreport_280912.pdf\&ei=jvNU5nqEqHGOAW0r4D4CQ\&usg=AFOjCNEcDvTS WtNPjn620LGFh50hSqK4DQ\&bvm=bv.681918 37,d.b2k . Acesso em 3 de Junho de 2014.

ZAL00M, Caitlin.

(2006). Out of the Pits: Traders and Technology from Chicago to London. Chicago, The University of Chicago Press.

(2003). Ambiguous numbers: trading technologies and interpretation in financial markets. American Ethnologist, vol.30, n.2, p.258-272.

\section{Recebido em}

dezembro de 2016

\section{Aprovado em}

março de 2017 